\title{
The role of natural thermal cycles on a limestone cliff mechanical behaviour
}

\author{
M. Gasc-Barbier ${ }^{a, *}$, V. Merrien-Soukatchoff ${ }^{\mathrm{b}}$, D. Virely ${ }^{\mathrm{c}}$ \\ ${ }^{a}$ Cerema, GeoCoD, avenue Albert Einstein, CS 70499, 13593 Aix-en-Provence, Cedex 3, France \\ ${ }^{\mathrm{b}}$ GeF, EPNO1, Cnam, Paris, France \\ c Cerema, 31400 Toulouse, France
}

Rock instabilities can represent major risks for local populations depending on their geographical location. Even if different mechanisms are known to trigger rockfalls such as precipitation, seismic activity and freezing, many rockfalls occur during periods when such trigger mechanisms are absent. Some recent studies have pointed out the role of thermal cycling in crack initiation or propagation. Here we use data from nearly five years of field monitoring of a French limestone cliff. Evolution of the aperture of joints were followed as well as displacements and temperature deep in the rock mass. We show that seasonal thermal variation affects the rock at depths of up to $6 \mathrm{~m}$ and subcritical cracking can probably appear even at this depth.

\section{Introduction}

Rockfall is one of the major risks that can occur not only in steep mountain terrain but also in plains when the rivers have dug hard rock and left cliffs. Various factors can explain rockfalls: in the Alps Gunzburger, Merrien-Soukatchoff, and Guglielmi (2005) cite sharp topographic contrasts, intensive previous tectonic deformations leading to a high degree of fracturing, seismic activity and precipitation profiles with rainfall concentration over time.

The causes of failure are diverse (Cloutier, Locat, Charbonneau, and Couture, 2015; Fell et al., 2008), and the triggering factor is often difficult to determine, but the action of weathering is significant in landscape evolution. In fact, many studies, based on site investigation, pointed out the importance different agents of weathering such as freezing (Deprez, De Kock, De Schutter, and Cnudde, 2020; Frayssines and Hantz, 2006; Matsuoka, 2008, 2001), rain (Galeandro, Doglioni, Simeone, and Šimůnek, 2014; Intrieri, Gigli, Mugnai, Fanti, and Casagli, 2012; Nguyen, Lee, and Kim, 2020; Regmi, Yoshida, Dhital, and Devkota, 2013; Stoffel, Tiranti, and Huggel, 2014) or thermal variations (Collins and Stock, 2016; Eppes, McFadden, Wegmann, and Scuderi, 2010; Eppes and Griffing, 2010; Eppes and Keanini, 2017; Gunzburger, Merrien-Soukatchoff, and Guglielmi, 2005; Hall, 2004, 1999; Hall, Thorn, and Sumner, 2012; Hall and Thorn, 2014; Holzhausen, 1989; Ravaji, Alí-Lagoa, Delbo, and Wilkerson, 2019; Vargas, Chavez,
Gusmao, and Amaral, 2009; Vargas, Castro, Amaral, and Figueiredo, 2004). Changes in temperature are one of the agents of the alteration to which attention has been drawn due to several events where other causes could not be invoked (Gunzburger, Merrien-Soukatchoff, and Guglielmi, 2005; Vargas, Chavez, Gusmao, and Amaral, 2009; GascBarbier and Merrien-Soukatchoff, 2019).

Studies focussing on thermal stress weathering were realised on different rock types: alluvial fans, boulders (Eppes, McFadden, Wegmann, and Scuderi, 2010; Eppes and Griffing, 2010), outcrops (Holzhausen, 1989) or quarry (Marmoni, Fiorucci, Grechi, and Martino, 2020), dome rock (Collins et al., 2018) or rock slopes (Gunzburger, Merrien-Soukatchoff, and Guglielmi, 2005; Vargas, Chavez, Gusmao, and Amaral, 2009) and different mineralogy: gneiss, granite, marble, ... Most of those studies are based on surface observations with (BakunMazor, Hatzor, Glaser, and Carlos Santamarina, 2013; Collins et al., 2018; Collins and Stock, 2016; Gasc-Barbier and Merrien-Soukatchoff, 2019; Gunzburger and Merrien-Soukatchoff, 2011; Holzhausen, 1989; Marmoni, Fiorucci, Grechi, and Martino, 2020) or without (Hall, Thorn, and Sumner, 2012; Hall and Thorn, 2014) instrumentation on the site. The two longest records are located in North America: an exfoliation sheet in the Yosemite Valley was monitored for 3.5 years (Collins and Stock, 2016) and temperature, light intensity, humidity and crack aperture have been recorded, and a small active rockslide in Gaspésie (Canada) was monitored with crackmeteers and other monitoring

\footnotetext{
* Corresponding author.

E-mail address: muriel.gasc@cerema.fr (M. Gasc-Barbier).
} 
techniques for 4 years, to achieve sufficient spatial and temporal resolutions to characterise the displacements of the rockslide (Cloutier, Locat, Charbonneau, and Couture, 2015).

Both papers study the role of thermal stress weathering based on surface monitoring (crackmeters, surface extensometers, strain gauges, ...) but thermal variation also affects the rock in depth. Dangerous rockfall hazard consists in rather larger rock blocks than "just" exfoliation sheets and the mechanisms of breakage, even if not completely understood is not only superficial. However, for larger blocks, the role of geology is predominant: and furthermore, the nature and location of structural joints, weak intercalation and natural stresses should be taken into account to understand the zones of weakness and the evolution over time of the rock mass, but a good knowledge of geometry in depth is difficult to achieve. Thus, it is interesting to understand the evolution of strain or temperature in the rock mass close to the surface. While many studies have been carried out around the evolution of temperatures in depth, they are generally carried out at the scale of the geothermal gradient and very few consider the very first metres behind a rockwall (Gasc-Barbier and Merrien-Soukatchoff, 2019; Gunzburger, MerrienSoukatchoff, and Guglielmi, 2005) which is the case of the data recorded in La Roque-Gageac site that are described below.

After the failure of a part of a limestone cliff in the village La Roque Gageac in France and because no other triggering factor could be demonstrated, temperature variations were suspected. There were no measurements on the site at the time of the event $(08 / 01 / 2010)$, but afterwards the cliff was monitored to survey the remaining hazard and design the reinforcement. This allows to have a long chronicle of monitoring during almost 5 The temperatures and strains were recorded, along open fractures inside the rock mass, at depths of $2 \mathrm{~m}, 4 \mathrm{~m}$ and $6 \mathrm{~m}$ from the face of the cliff. These measurements allow analysing the role of temperature as potential failure factor.

\section{Geological and geomorphological settings, in situ device, and mechanical properties}

\subsection{Geological and geomorphological settings}

La Roque-Gageac is a small village in the south-west of France, just a few miles away of the famous prehistoric site of Lascaux. This small village (about 400 citizens) is sandwiched between a massive limestone cliff and the Dordogne River. It prides itself on the dramatic cliffs above the village, but it is also a source of hazards. Tourism, with about 2 million visitors a year, is a major asset for local economy. The climate of the site is temperate with an oceanic dominant influence. In winter, it may also undergo mountain influences which are consequences of the relative proximity to the Massif Central. Conversely, in summer, the region can undergo hot air flows from the Mediterranean. Over the period from December 1995 to January 2014, in Sarlat (less than $10 \mathrm{~km}$ near La Roque-Gageac), minimal negative temperatures are reached once a day for 50 days per year on average but only for 7.4 days/year under $-5{ }^{\circ} \mathrm{C}$.The mean temperature per month is between $5.7^{\circ} \mathrm{C}$ (in December) and 20.9 (in July and August); maximum annual temperatures in the area are between $27^{\circ}$ and $32{ }^{\circ} \mathrm{C}$ and minimum temperatures between $-10^{\circ} \mathrm{C}$ and $-15^{\circ} \mathrm{C}$. Average annual rainfall is $855 \mathrm{~mm}$, the maximum amount of precipitation recorded in one day was reached in April 2001 with $70 \mathrm{~mm}$ which is not such a high value. Precipitation greater than $10 \mathrm{~mm}$ occurs between 1.7 and 3.1-day/month, on average, over the period.

The cliffs above the village, about $60 \mathrm{~m}$ to $80 \mathrm{~m}$ high, are constituted of the middle and superior part of Coniacian limestone and subject to current or past karst phenomena. These networks, active or inactive, significantly weaken the rock-mass and are part of the aggravating factors in the overall susceptibility of the cliff to block fall hazards. The ubiquity of visible karsts on the cliffs facing La Roque Gageac and the presence of a paleo-polje not far away confirm the past intense activity. But the actual karst system is "perched" and it is now above its natural outlet, the Dordogne River because its vertical development was interrupted by an impermeable layer. Meteoric water on limestone plateaus is almost exclusively drained to deep karst systems by many dry valleys and sinkholes, resulting in the vertical surface of the cliff being dry. Anyway, the cavity under study belongs to an inactive part of the network also called paleo-karst but is dry. Indeed, in our survey, we found that all the observed upper karst system was, at various levels, blocked by rich sandy clay fillings iron oxides.

Around the studied cave described subsequently, the rock can be depicted as a bioclastic microcrystalline sandy limestone with important lateral variability. A more detailed description of the geology and a geological map are given in Gasc-Barbier, Merrien-Soukatchoff, and Villarraga-diaz (2020).

The tectonic phenomena affecting the region are small. We observed a wide undulation forming a faulty anticline fold and a synclinal fold from the north-west south-east axis (N120 ) showing very weak dips. This undulation would be prior to the Santonian, so it affects the Coniacian. The tectonic accident closest to La Roque Gageac is about $30 \mathrm{~km}$ away, it is a fault, oriented $\mathrm{N} 130^{\circ}$, which shifts the terrain from the Upper Cretaceous to the Santonian with a discharge of about $150 \mathrm{~m}$. Thus, no major tectonic fracture affects the rock mass.

Four major rockfalls have been identified above the village at La Roque Gageac since the beginning of the 20th century (see Fig. 1).

- 1920: collapse of an eastern section of the village

- 17/01/1957: collapse of a large section of western part of the rock cliff; three people -and a donkey- died.

- 1994: small blocks collapse in the centre part of the cliff.

- 8/01/2010: in the morning collapse of a part of the roof of a perched cave. This cave was used in the Middle Ages as a small stronghold for the Bishop of Sarlat during the religious wars.

The mass that collapsed on the 8th of January 2010 was about 350 tons. The debris was removed few months after the collapse, but a part of the roof (about 350 tons as well), called "the unstable beam", remained in place. Some instrumentation was placed to survey the remaining hazard because of the village below the cave but we also took the opportunity to get more data on the behaviour of the rock mass.

Among author factors the possible role of temperature was invoked to explain this collapse leading, retrospectively, to investigative measurements on this issue. For this reason, the precise moment when the phenomenon started may be important, but the only information available is that the detachment of the block from the vault of the troglodyte cave took place on January 8 at 9 a.m., yet the previous day, during the night at 1.30 a.m., the closest neighbour heard an abnormal noise, without being able to determine its origin.

\subsection{In situ device}

Fig. 2 and Fig. 3 display the hazard zone while Fig. 4 presents a scheme of the cave where a part of the roof had collapsed, and the

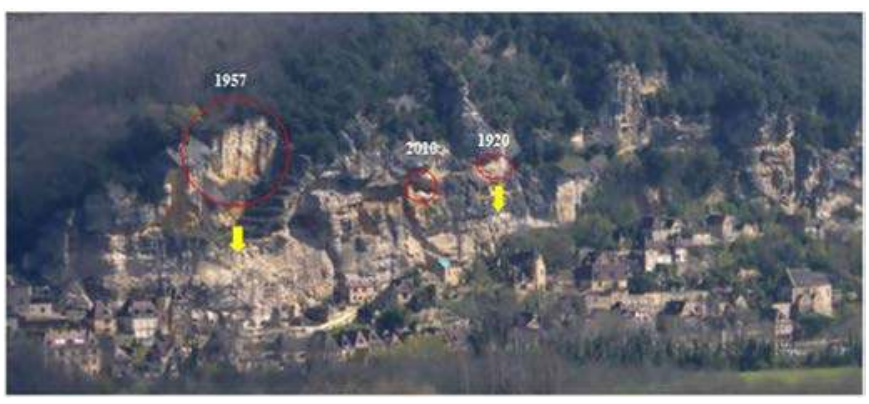

Fig. 1-. Location of the rockfall above the village and location of the cave under study (2010 rockfall). 


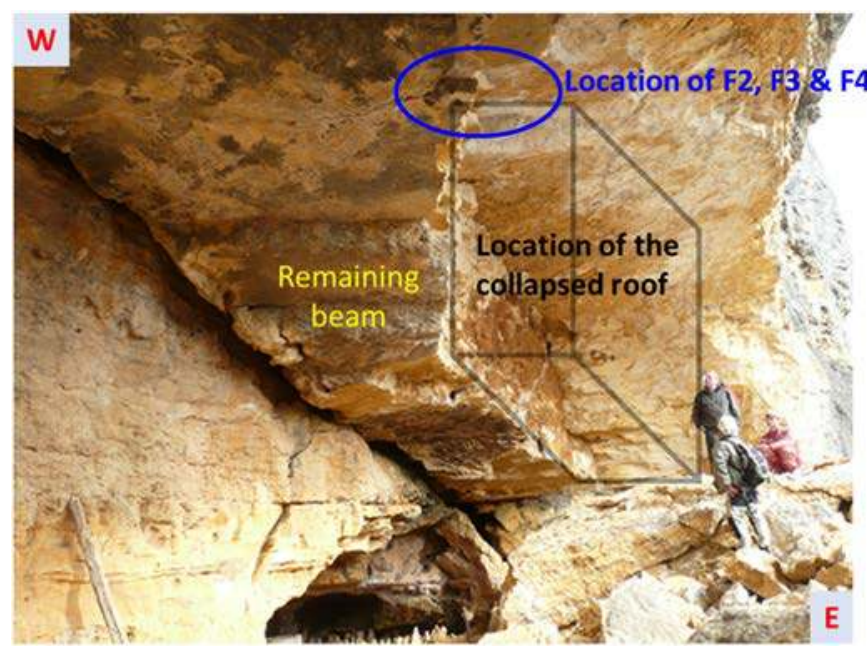

Fig. 2. - West view of the perched cave just after the collapse of the roof -the collapsed rock can be seen on the floor of the cave under the men standing who provide the scale- fissurometers were not in place at the time of the picture.

unstable beam. The remaining beam is delimited by a horizontal interlayer thinning from east to west, hanging to the roof of the cave at the west and east-clamped in the rock mass. Opened fractures can be observed all around the beam. In order to assess the remaining hazard, a monitoring of the joints opening around the beam was realised with 4 fissurometers (F1 to F4) that measure displacements, and a temperature probe was installed on the roof of the cave. In the meantime, borehole extensometers (D1 and D2) were drilled above the cave to understand the global behaviour of the rock mass. An extensive presentation of the monitoring device can be found in (Gasc-Barbier et al., 2020; GascBarbier et al., 2015) and is summarised below.

The four fissurometers were positioned around the remaining beam to quantify the aperture (opening or closing) of the joints, in order to evaluate the relative movement of the blocks, according to changes in external conditions: F1 near the east-clamped end of the beam, and the three others on the west part (Fig. 3): Two of them (F3 and F4) were fixed across a horizontal joint and a vertical joint respectively, F2 is positioned across the vertical joint in a $45^{\circ}$ angle. A thermal probe was also fixed on the roof of the cavity near the three fissurometers to register the evolution of the temperature in the cave. Fissurometers are LVDT strain gauges that measure displacements between their two extremes with a resolution of 1/10th mm. From July 2010 to April 2015, a value per hour was recorded except for a few periods.

The borehole extensometers (D1 \& D2) are RockTest / Télémac distofor@ anchored in the rock mass at the end of the borehole at a depth of $8 \mathrm{~m}$ from the cliff wall. Both were prepared with three displacements measuring points at depths of $2 \mathrm{~m}, 4 \mathrm{~m}$ and $6 \mathrm{~m}$ from the cliff wall and temperature measuring points at $2 \mathrm{~m}$ and $6 \mathrm{~m}$ depth (see Fig. 5). Their positions above the cave are shown on Fig. 3.

The supplier gives a measuring range of $100 \mathrm{~mm}$, a resolution lower than $0.01 \mathrm{~mm}$. Given the length of the rods used $(8 \mathrm{~m})$, the precision is about $0.05 \mathrm{~mm}$. The operating temperature must remain between $0^{\circ}$ and $50{ }^{\circ} \mathrm{C}$. The devices were placed perpendicular to the rock face, about $4 \mathrm{~m}$ and $7.5 \mathrm{~m}$ above the roof of the cave cavity (Fig. 4). From July 2010 to April 2015, a value per hour was recorded, except for some few periods.

Measurements were stopped in April 2015 because of reinforcement works in the cave in order to secure the village.

\subsection{Physical and mechanical properties of the limestone}

Physical characterisation of the limestone realised in our lab gives the following means (Villarraga, Gasc-Barbier, Vaunat, and Darrozes, 2018):

- Density $\rho=2382(+/-45) \mathrm{kg} / \mathrm{m}^{3}$

- $\mathrm{V}_{\mathrm{p}}=4651(+/-545) \mathrm{m} / \mathrm{s}$

- $V_{s}=2671(+/-174) \mathrm{m} / \mathrm{s}$

- Total porosity $\mathrm{n}_{\mathrm{t}}=17.9 \%$

- Connected porosity $\mathrm{n}_{\mathrm{c}}=11.2 \%$

- Water ratio, $\mathrm{w}=4.7 \%$

The uniaxial compression strength was measured on 10 samples (50 $\mathrm{mm}$ in diameter -2 in slenderness). The mean value is $47.4 \mathrm{MPa}$ with a standard deviation of 9.63 MPa. This standard deviation is quite high and characterises a heterogeneous rock. The heterogeneity can be

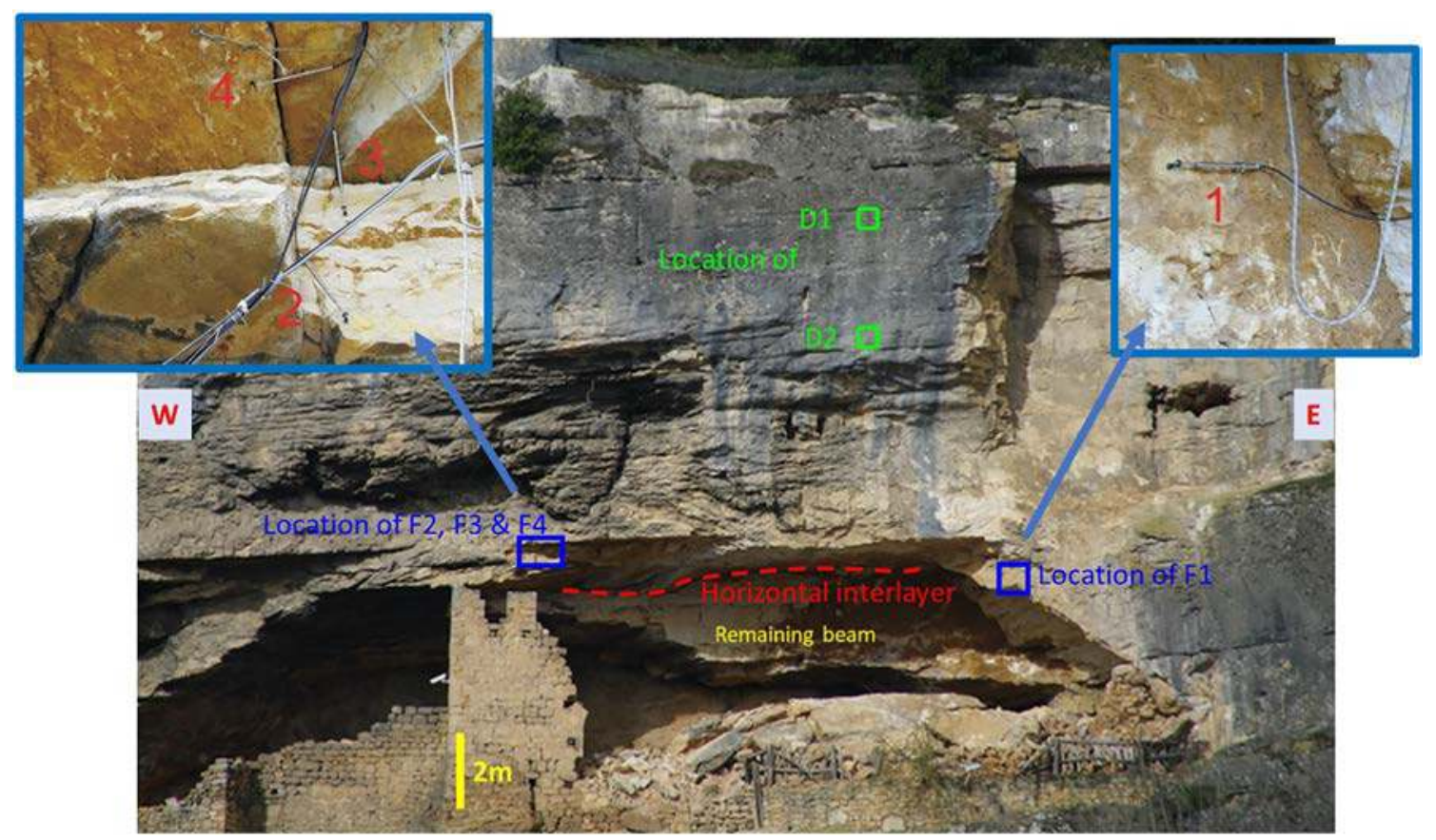

Fig. 3. - Front view of the perched cave just after the collapse of the roof. 


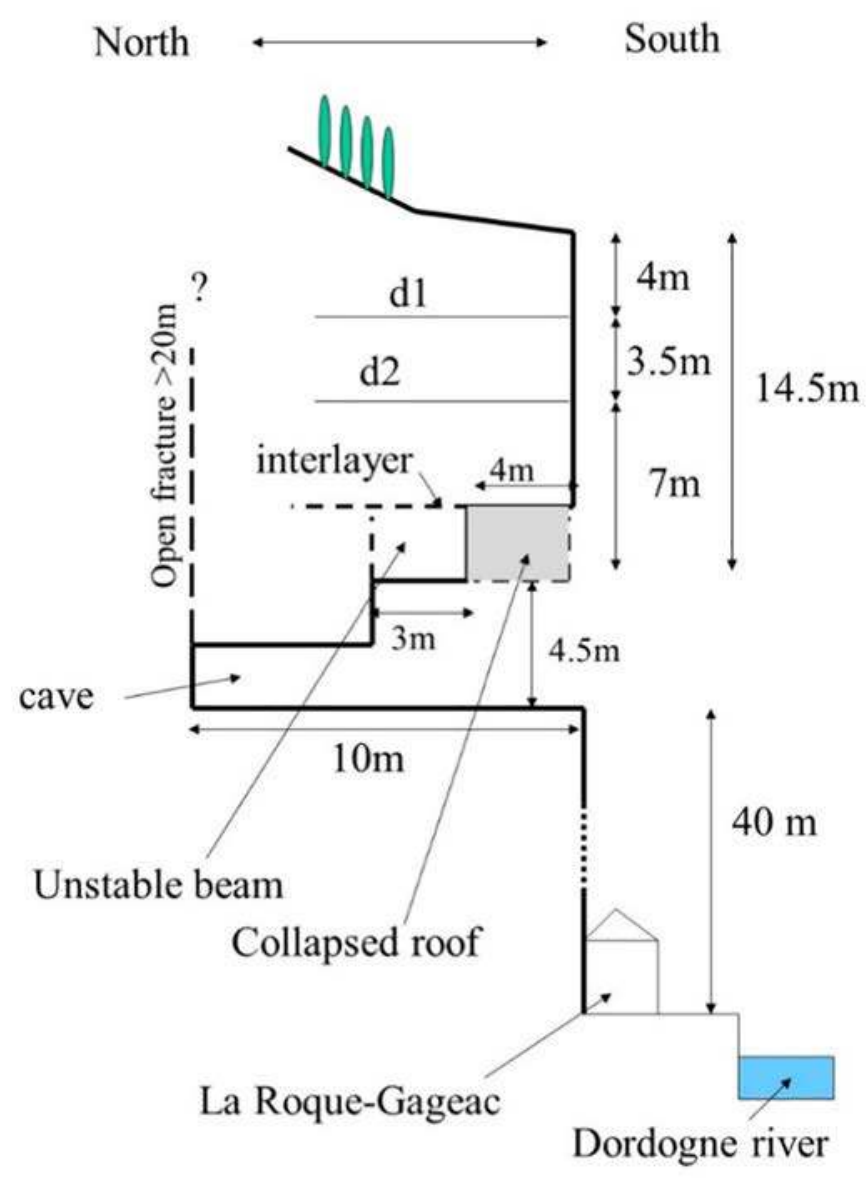

Fig. 4. - Schematic cross-section of the perched cave.

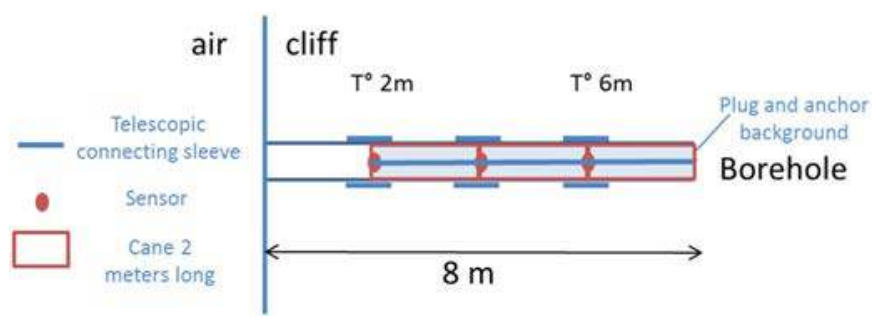

Fig. 5. - Schematic cross-section of a borehole extensometer.

attributed to the heterogeneous arrangement of elements (bioclasts) and/or variable cementation even on a centimetre level.

Indirect tensile strength was obtained using Brazilian tests on 11 samples. A mean value of 5.4 MPa and a standard deviation of $0.5 \mathrm{MPa}$ was obtained. Triaxial tests were also performed on $50 \mathrm{~mm}$-in diameter samples. Results are given in Table 1.

Following the European standard EN 14-581, linear thermal expansion coefficient $(\alpha)$ was measured at Toulouse Cerema laboratory on two cubic blocks $(10 * 10 * 10 \mathrm{~cm})$. It was also measured on two cylindrical samples (50 $\mathrm{mm}$ in diameter $-100 \mathrm{~mm}$ high) using the same

Table 1

Results of triaxial tests on La Roque-Gageac limestone.

\begin{tabular}{llll}
\hline$\sigma_{3}(\mathbf{M P a})$ & $\boldsymbol{\sigma}_{\mathbf{1}}(\mathrm{MPa})$ & $\mathrm{E}(\mathrm{GPa})$ & $\boldsymbol{\nu}$ \\
\hline 0.0 & 47.4 & & \\
2.5 & 65.0 & 38.4 & 0.15 \\
5.0 & 80.2 & 42.6 & 0.15 \\
10.0 & 81.7 & 47.0 & 0.12 \\
\hline
\end{tabular}

thermal solicitation. Strain gauges were glued on the three opposite phases of the cubic blocs and thus gave three values of the linear thermal expansion coefficient for each sample whereas only two values, axial and circumferential, were obtained on cylindrical samples. We finally obtained nearly the same value whatever the shape of the sample: $\alpha=6$ $(+/-3) 10^{-6} \mathrm{~K}^{-1}$. The variability is due to heterogeneity and slight anisotropy of the rock. The role of anisotropy should be analysed more deeply, but our samples were drilled from one of the felled blocs as can be seen on Fig. 2 that we were not able to orient.

\section{In situ measurements and recording}

All temperature and displacement records are free of access, published in Mendeley Database under the name ThermoMechaLimestone (doi: 10.17632/wnt6thwzvp.1).

\subsection{Temperature recording}

\subsubsection{Temperature recording in the cave}

The temperature sensor hanging from the roof of the cave shows that the hourly variation of temperatures is often less than a degree. From time to time, much more significant hourly variations were measured: + $12.4^{\circ}$ on $06 / 04 / 2011$ between 12 and 13 p.m. and $-8,43^{\circ} \mathrm{C}$ on $20 / 09$ / 2014 between 4 and 6 p.m. The maximum temperature recorded on the site was $47.4^{\circ}$ on $09 / 09 / 2001$ (at 4 p.m.). Negative temperatures were occasionally recorded the first two winters, a minimum temperature of $-6.5{ }^{\circ} \mathrm{C}$ was recorded on $02 / 09 / 2012$ at 9:00. Between two consecutive measurements $(1 \mathrm{~h})$ the maximum temperature increase was $+12.5^{\circ} \mathrm{C}$ / $\mathrm{h}$ (on 04/04/2011 between 12:00 a.m. and 1:00 p.m.) and the maximum decrease was $-7^{\circ} \mathrm{C} / \mathrm{h}$ (on 05/10/2012 between 6:00 and 7:00 p.m.).

The maximum daily temperature variation in the cave was recorded on 14/03/2012 where the temperature varied between 9:00 a.m. and 4:00 p.m. from $9.44{ }^{\circ} \mathrm{C}$ to $41,19^{\circ} \mathrm{C}$, which is an increase of $32{ }^{\circ} \mathrm{C}$ in $7 \mathrm{~h}$. This maximum increase was followed the next night by a decrease of $31^{\circ} \mathrm{C}$ in $16 \mathrm{~h}$.

The reported temperature variations were measured inside the cavity, while those at the surface of the rock mass could be more important on the faces exposed to sunlight (Gunzburger and Merrien-Soukatchoff, 2011).

\subsubsection{Temperature recording in the rock mass}

As explain in the experimental device, temperature was measured in the cave but also in the extensometers at 2 and $6 \mathrm{~m}$ depth. Fig. 5 presents the evolution of the temperature during the 5 instrumented years in the rock mass at 2 and $6 \mathrm{~m}$ depth (Fig. 6a) and in the cave (Fig. 6b). We can observe a decrease of the amplitude of the temperature variation when going deeper in the rock mass which is consistent with conduction phenomena.

The amplitudes of the temperature decrease with depth over the whole period which is consistent with the conduction hypothesis. To estimate conduction parameters, the rock mass is assimilated to a semiinfinite medium and the main wall to a free surface. A Fourier decomposition was performed to determine an in situ diffusivity "a".

Assuming only conductivity, for a semi-infinite ground, the temperature at depth $\mathrm{z}$ can be expressed as (Carslaw and Jaeger 1986):

$T(z, t)=T_{0}+\sum_{n=1}^{\infty} A_{n}(z) \cos \left(n \omega t-\varphi_{n}(z)\right)$

with a mean temperature of $\mathrm{T}_{0}$ and an angular frequency of $\omega=$ $\frac{2 \pi}{\text { period }}$ rad.s s. $^{-1}$

$A_{n}(z)$ represents the half-amplitude of the $n^{\text {th }}$ harmonic $\left(n^{\text {th }}\right.$ partial "temperature wave") at depth $\mathrm{z}$, and $\varphi_{\mathrm{n}}(\mathrm{z})$ represents its phase.

If the hypotheses are satisfied, the exponential amplitude of the harmonics are linked to the in situ thermal diffusivity "a" of the rock by the relation: 


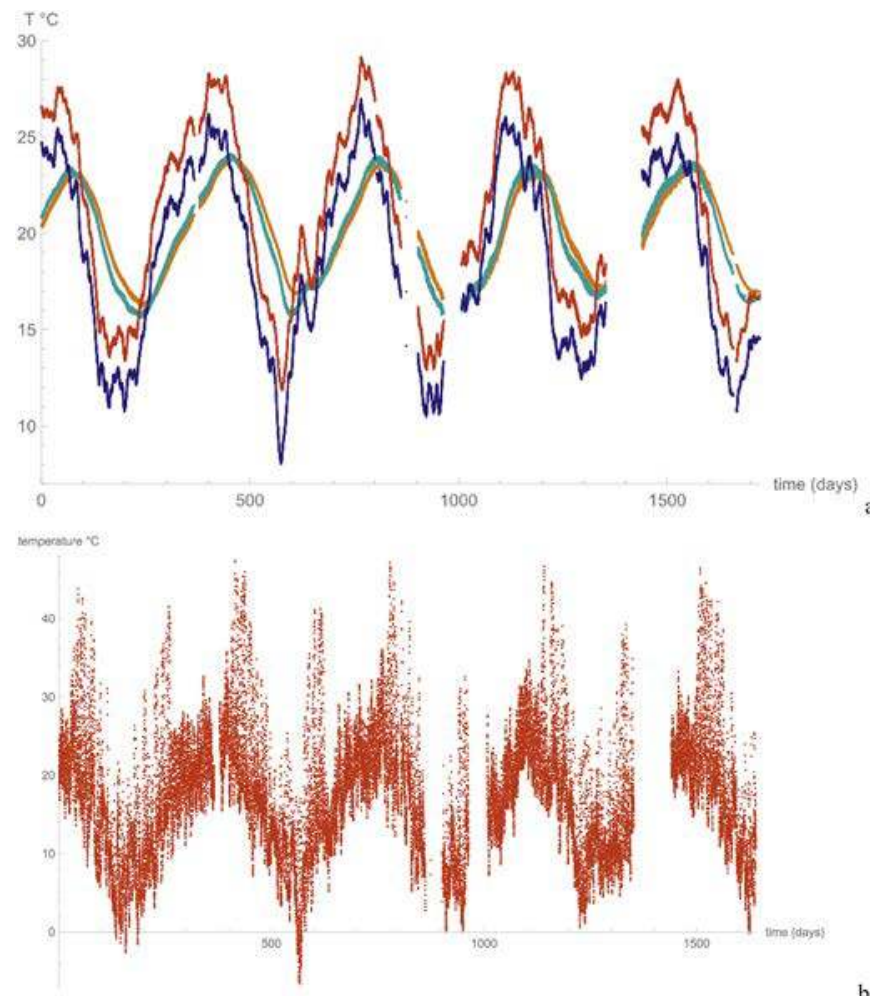

Fig. 6. - Temperature, a-in D1 ( $2 \mathrm{~m}$ : red, $6 \mathrm{~m}$ : orange) and D2 (2 m: dark blue, $6 \mathrm{~m}$ : light blue; b- in the cave (with the temperature probe) a point per hour. The series presented some gaps corresponding to some days to 2 weeks of lack of measurements. (For interpretation of the references to colour in this figure legend, the reader is referred to the web version of this article.)

$\frac{\ln A_{n}(z)}{\sqrt{n}}=\frac{\ln A_{n}}{\sqrt{n}}-z \sqrt{\frac{\omega}{2 a}}$

The linear increase of the phase lag with depth is also linked to the in situ thermal diffusivity "a":

$\frac{\varphi_{n}(z)}{\sqrt{n}}=\frac{\varphi_{n}}{\sqrt{n}}-z \sqrt{\frac{\omega}{2 a}}$

The thermal diffusivity "a" of the rock can then be obtained for the different harmonics from the decrease of amplitude or from the phase lag between the recording at two depths: $a=\frac{\pi}{\tau} \cdot\left[\frac{(\mathrm{z} 1-\mathrm{z} 2) \cdot \sqrt{\mathrm{n}}}{\ln \mathrm{A}_{\mathrm{n}}(\mathrm{z} 1)-\ln \mathrm{A}_{\mathrm{n}}(\mathrm{z} 2)}\right]^{2}$

$a=\frac{\pi}{\tau} \cdot\left[\frac{(\mathrm{z} 1-\mathrm{z} 2) \cdot \sqrt{\mathrm{n}}}{\varphi_{\mathrm{n}}(\mathrm{z} 1)-\varphi_{\mathrm{n}}(\mathrm{z} 2)}\right]^{2}$

In our site we have temperature recordings at 2 and $6 \mathrm{~m}$ in the two extensometers. Although the means of temperatures are slightly different at $2 \mathrm{~m}$ and $6 \mathrm{~m}$ and for both extensometers and between the two extensometers, they can be fitted to a Fourier serie (Fig. 7) and we interpreted the amplitude decreasing and the phase lag for the two extensometers, for the consistent harmonics. The order of magnitude of the diffusivity is 2-3 $10^{-6} \mathrm{~m}^{2} \cdot \mathrm{s}^{-1}$ which is about the same order of magnitude as the value provided by Fortin, Gasc-barbier, and Merriensoukatchoff (2018) for limestone that is $1.110^{-6} \mathrm{~m}^{2} \cdot \mathrm{s}^{-1}$.

Although the analytical interpretation could be improved by an estimation of heat flux and solar radiation as proposed by Gunzburger and Merrien-Soukatchoff (2011), it was not realised because an accurate analytical estimation is difficult considering the morphology of the cliff and the cave.

\subsection{Displacements recordings}

Non-smoothed curves of displacement time for the four fissurometers and both extensometers are presented in Gasc-Barbier, MerrienSoukatchoff, and Villarraga-diaz (2020). We only concentrate here on the main results. The records began in July 2010, when the temperature was about $24.5{ }^{\circ} \mathrm{C}$ in the cave and $20.5^{\circ} \mathrm{C}$ at $6 \mathrm{~m}$ depth. Globally, the four fissurometers behave in a similar way, even if their displacement amplitude is different. We observed a total displacement amplitude ranging from $0.4 \mathrm{~mm}$ for $\mathrm{F} 1$ to almost $3.5 \mathrm{~mm}$ for $\mathrm{F} 3$ and $\mathrm{F} 4$ against 1.5 $\mathrm{mm}$ for F2 that will be detailed subsequently. Thanks to the long duration of the recordings, we were able to observe a seasonal variation of the crack openings when looking at the displacements versus time curves: as the recordings started in July, we could globally observe an opening of the cracks (positive strain slope) in the spring and in the summer and a closing of cracks (negative strain slope), in autumn. In winter we note a stagnation of the strain.

Both borehole extensometers have 3 measurement points, at 2, $4 \mathrm{~m}$ and $6 \mathrm{~m}$ from the cliff wall. Again, all the records are not presented here (see Gasc-Barbier, Merrien-Soukatchoff, and Villarraga-diaz (2020)), only the main results: D1 and D2 show that displacements are all the more important as they are measured near the external surface: the amplitude of the displacements measurement at $2 \mathrm{~m}$ depth is larger than the one recorded at $4 \mathrm{~m}$ depth, and both are also larger than the amplitude of the displacements recorded at $6 \mathrm{~m}$ depth; which is consistent with thermomechanical behaviour govern by external
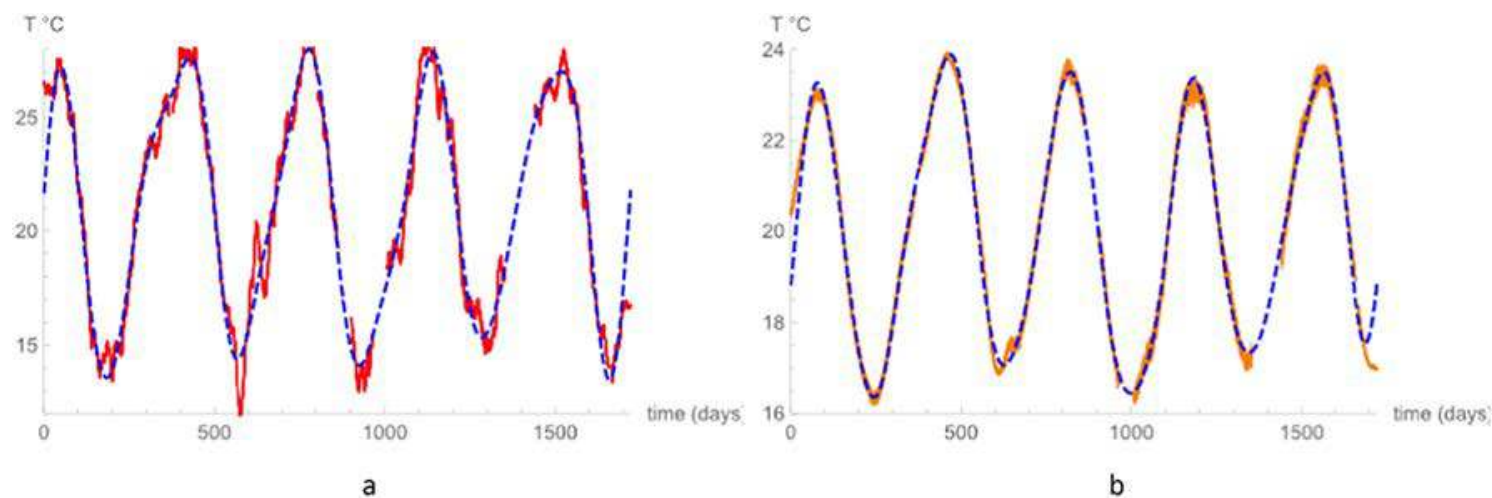

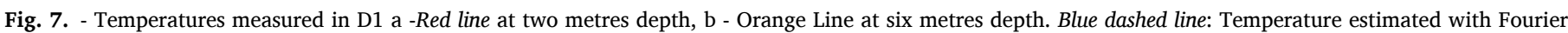

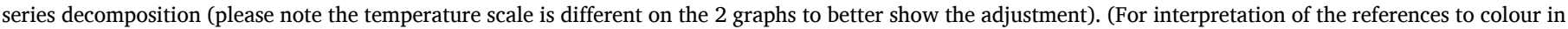
this figure legend, the reader is referred to the web version of this article.) 
temperature. Temperature is inversely correlated to the displacements. Deformations recorded at a $6 \mathrm{~m}$ depth on both extensometers have very similar amplitudes, about $0.1 \mathrm{~mm}$ and the maximum amplitude $(1.75$ $\mathrm{mm}$ ) is recorded on D1 at a $2 \mathrm{~m}$ depth.

\subsection{Correlation between displacement and temperature}

Another way to study the behaviour of the rock mass is to look at the displacement versus temperature curve. Fig. 8 and Fig. 9 display the relation between displacement and temperature on F2 and on D1 at $6 \mathrm{~m}$ depth. As can be seen on Fig. 6b, curves were smoothed to be more readable since a point per hour for both measurement points implied a lot of daily variations. On Fig. 8, when observing an annual cycle, we can see that overall displacements change little when temperature varies a lot and then an increase (or decrease) of displacements is observed with small global temperature variation. It behaved just as if the displacement was not caused by the variation of temperature alone, but that the cracks are open because of the accumulation of temperature. After 1year recording, a hysteresis on the curve displacements/temperature is observed, and as plotted on Fig. 8, a permanent displacement of about $0.21 \mathrm{~mm}$ can be detected, then 0.42 during the year $2,0.18 \mathrm{~mm}$ during year 3 , and finally $0.07 \mathrm{~mm}$ during year 4 . This gives about $0.88 \mathrm{~mm}$ after four years on F2. Similar behaviours can be observed on the other fissurometers even if permanent displacement is smaller. Similar observations can also be made on extensometer recording, even at $6 \mathrm{~m}$ depth: Fig. 9 shows the relation between displacement and temperature on D1 at $6 \mathrm{~m}$ depth. Over the whole recorded period, a slight permanent displacement of $0.015 \mathrm{~mm}$ after 5 years appears. At $2 \mathrm{~m}$ depth (not shown on the figures), it is more significant: $0.43 \mathrm{~mm}$ on D1 and 0.25 $\mathrm{mm}$ on $\mathrm{D} 2$.

As permanent displacements are observed in all equipment and on both depths, it cannot be attributed to instrumental drift or creep. Other explanations will be proposed below.

Dots correspond to each July 22nd that is one year of recording

\section{Discussion}

\subsection{What is the driving force for the observed displacements?}

The monitoring system and specially the fissurometers made it possible to understand the overall behaviour of the beam and to secure the site, while waiting for the reinforcement works which was the first priority.

The recorded data clearly show the role of temperature on the surface and in depth on displacements. Before discussing the possible role of temperature on crack initiation or propagation and thus to rocky instabilities, let us examine the possible liability of other factors.

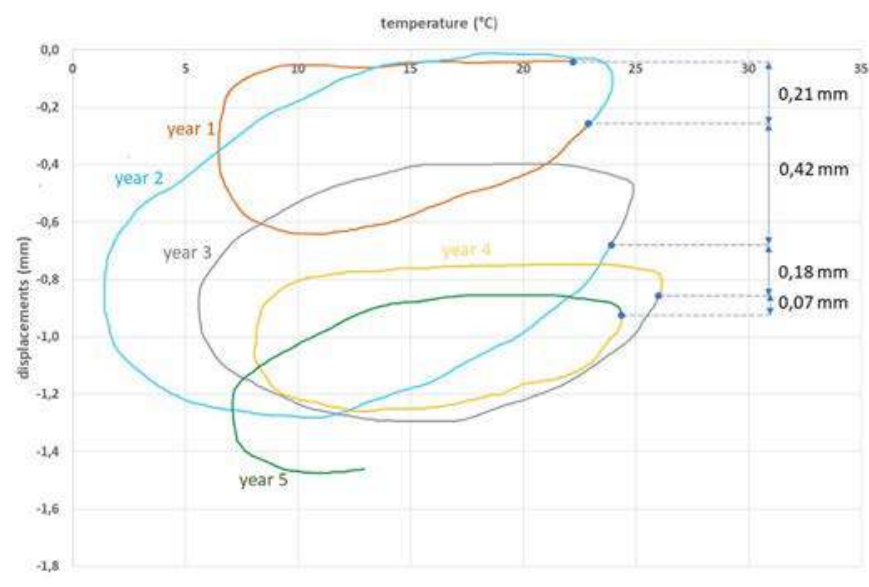

Fig. 8. - Correlation between length variation and temperature on F2.

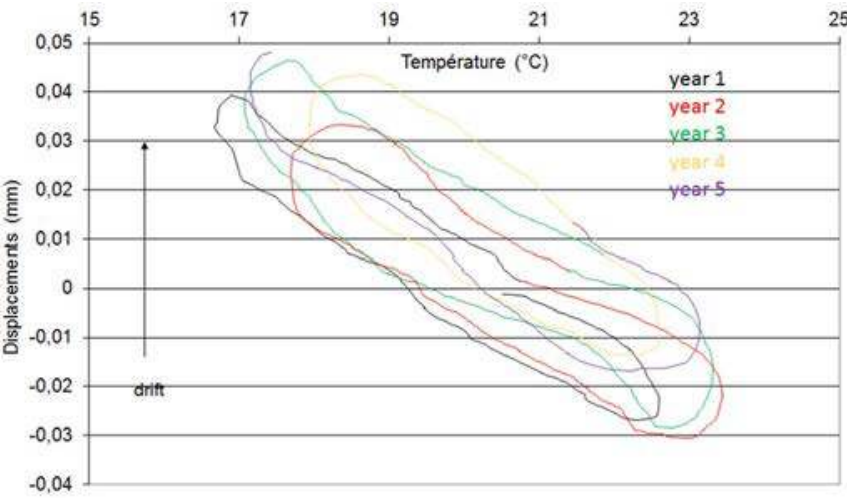

Fig. 9. -Length variation versus temperature for the D1-6 $\mathrm{m}$ depth extensometer- Colour change each July 22nd that is one year of recording. The resolution of the extensometer is less than $0.01 \mathrm{~mm}$.

Main triggering factors considered for rockfall are seismic activity, frost and precipitation.

Seismic activity: the French government published in 2011 a seismic zoning of France. Our site is classified as "very low seismic hazard" that is the lowest possible class. That does not mean that no earthquake can occur, but that none was ever recorded in the area, and there was no seismic activity in January 2010.

Precipitation: The meteorological information was discussed in section 2.1 above, and no significant rain event was spotted prior to the January 2010 event. The cave belongs to an inactive part of a paleokarst. Whenever we went on the site when it rained, no water exuded from the monitored joint. However, some water was observed in larger discontinuities, such as the open fracture mentioned on Fig. 4. It seems more likely that water flows along the karst network. That does not mean that hydromechanics should not be explored but it seems that it is not the main point to be considered on the monitored fractures.

Frost: As seen on Fig. 6, at $2 \mathrm{~m}$ depth and, furthermore, at $6 \mathrm{~m}$ depth, recorded temperature is never less than $7.8^{\circ} \mathrm{C}$. No frost can occur in the rock mass. However, on the temperature probe in the cave, a few days nearly each year are recorded with subzero temperature. Again, we think that even if frost can locally induce fracture propagation it is not the main point to be considered.

The driving force of the recorded displacements is clearly temperature and, because other causes of failure were difficult to envisage, we detailed subsequently how thermal variations can influence stresses and lead to failure in the rock matrix or fracture propagation.

\subsection{Thermomechanics approach}

4.2.1. hermoelasticity and possible tensile failure of the rock matrix

Let us consider a semi-infinite medium submitted to temperature variations.

For a homogeneous and isotropic material, in thermoelasticity, the relationship between stress variation and associated strains are (Henry and Parsy, 1982):

$\Delta \sigma_{\mathrm{ij}}=\frac{\mathrm{E}}{(1+\nu)} \cdot \varepsilon_{\mathrm{ij}}+\frac{\nu \cdot \mathrm{E}}{(1+\nu) \cdot(1-2 \nu)} \cdot \operatorname{tr} \varepsilon \cdot \delta_{\mathrm{ij}}-\frac{\mathrm{E}}{(1-2 \nu)} \alpha \cdot \Delta \mathrm{T} \cdot \delta_{\mathrm{ij}}$

$\varepsilon_{i j}=\frac{1+\nu}{E} \cdot \Delta \sigma_{\mathrm{ij}}-\frac{\nu}{\mathrm{E}} \cdot \operatorname{tr} \Delta \sigma_{\mathrm{ij}} \cdot \delta_{\mathrm{ij}}+\alpha \cdot \Delta \mathrm{T} \cdot \delta_{\mathrm{ij}}$

E: Young modulus, $\nu$ Poisson's ratio and $\alpha$ linear thermal expansion coefficient.

Let $z$ be the depth direction perpendicular to the surface. Using cylindrical coordinates, $r$ and $\theta$ are the axis perpendicular to the $z$-axis. Considering a semi-infinite medium, no stress is supposed to occur along $\mathrm{z}$ when temperature varied. It can be demonstrated that the strain 
(elongation for a positive variation of temperature) along the $z$-axis is given by:

$\varepsilon_{z}=\frac{1+\mathrm{n}}{1-\mathrm{n}} \cdot \alpha \cdot \Delta \mathrm{T}$

And the corresponding stress variations in the $(r, \theta)$ plane are:

$\frac{\Delta \sigma_{\mathrm{rr}}=\Delta \sigma_{\theta \theta}=-\alpha \cdot \Delta \mathrm{T} \cdot \mathrm{E}}{(1-\nu)}$

Which could be called $\Delta \sigma_{\perp \mathrm{z}}$

$\Delta \sigma_{z}=-\frac{\mathrm{E}}{1-\mathrm{n}} \cdot \alpha \cdot \Delta \mathrm{T}$

$\Delta T$ is the temperature variation at the corresponding depth.

These thermal stresses, added to the mechanical stresses, increase the traction when temperatures decrease (bear in mind that tensile stresses are counted positively). Table 2 gives an estimation of the stress variations induced by a given variation of temperature in La Roque Gageac case, that is a $42.6 \mathrm{GPa}$ Young modulus (E), a 0.15 Poisson's coefficient $(v)$ and a $6.10^{-6}$ linear thermal expansion coefficient $(\alpha)$.

If the stress modulus parallel to the surface is low, about zero (which have been confirmed by 3D modelling), 5,4 MPa, the tensile strength, is reached for a negative variation of about $18{ }^{\circ} \mathrm{C}$ and thus can explain a failure in the rock matrix. A decrease of temperature of $18,1{ }^{\circ} \mathrm{C}$ in $4 \mathrm{~h}$ was recorded the $20 / 09 / 2014$ in the cave, which suggests this variation, or more, is feasible at the surface of the rock mass.

\subsubsection{Fracture mechanics}

If tensile strength can explain some rupture in the rock matrix in specific configurations, fracture mechanics could also be explored. According to fracture mechanics, a crack can propagate according to three possible modes or a combination of these three modes. The analysis of the elastic stress field near a fracture lead (Griffith, 1924) to the notion of stress concentration factor (K). The $\mathrm{K}$ factor, generally expressed in $\mathrm{MPa} \cdot \mathrm{m}^{1 / 2}$, is a function of the geometry of the cracked material, the dimensions of the crack and the loading mode. The ability of a fracture to propagate is controlled by a threshold named fracture toughness. When $\mathrm{K}$ exceeds fracture toughness in a single load at a low speed, the crack propagates. Toughness is defined for each mode of rupture ( $\mathrm{K}_{\mathrm{IC}}$, $\mathrm{K}_{\mathrm{IIC}}$ and $\mathrm{K}_{\mathrm{IIC}}$ ). Analytical developments not presented here (Merriensoukatchoff and Gasc-barbier, 2021) show that as soon as the joint aperture reaches $4.4 \mathrm{~mm}$, fracture can propagate in mode I. And the larger the aperture, the easier the chance of a fracture to propagate in mode I and in mode II. If the decrease of temperature is greater than $18^{\circ} \mathrm{C}$, tensile failure in the rock matrix is the predominant phenomenon compared to crack propagation.

Yet crack can propagate due to fatigue at a stress concentration factor (K) lower than toughness (Atkinson, 1982), up to $10 \%$ of Kc according to Putot, Chastanet, Cacas, and Daniel (2001) especially when the fracture is subjected to cycling loading. The subcritical crack growth has been studied in rocks since the $80^{\prime}$ by Atkinson (Atkinson, 1982; Meredith and Atkinson, 1985). According to Eppes and Keanini (2017) "terms including "environmentally assisted cracking," "stress corrosion," "timedependent crack growth," "progressive failure," "microcracking" or

Table 2

Stress variation due to temperature variation, considering $\mathrm{E}=42,630 \mathrm{MPa}$ (mean of value of Table $1, \nu=0.15$ and $\alpha=610^{-6}$.

\begin{tabular}{ll}
\hline$\Delta \mathrm{T}\left({ }^{\circ} \mathrm{C}\right)$ & $\Delta \sigma_{\perp \mathrm{z}}(\mathrm{MPa})$ \\
\hline-5 & 1.5 \\
-10 & 3.0 \\
-15 & 4.5 \\
-14.6 & 4.4 \\
-17.9 & 5.4 \\
-21.2 & 6.4 \\
\hline
\end{tabular}

"static fatigue" are commonly synonymously employed to describe combined subcritical cracking processes"

\subsection{Thermal stress weathering}

Due to temperature variation, matrix failure can happen (for a decrease of temperature greater than $18{ }^{\circ} \mathrm{C}$ in our case) or cracks can grow quickly when fracture toughness is reached or slowly and steadily at stresses much lower than critical stresses. In this last case fatigue due to subcritical fracturing, need long-term exposure (10-10 6 years). Temperature variation could induce such fatigue that is generate thermal stress weathering.

Some recent paper proposed mathematical formulation of thermal stress weathering (Eppes and Keanini, 2017; Ravaji, Alí-Lagoa, Delbo, and Wilkerson, 2019). Eppes and Keanini (2017) formulation is based on kinetic laws: cracking rates are dependent on many factors including stress magnitude and the length of the crack for instance.

In addition, from a micro-structural point of view, it is well known that an increase in temperature induces a dilation of crystals (Fortin, Gasc-barbier, and Merrien-soukatchoff, 2018). This expansion can lead to the development of intergranular tensile compression stresses and, if they exceed the tensile strength, intragranular and intergranular cracking may occur. In the case of thermal fatigue (i.e. repetition of small temperature cycles just as daily temperature variation, this crack propagation can exist even for smaller stresses: that is subcritical crack growth (Atkinson, 1982; Meredith and Atkinson, 1985). According Eppes and Keanini (2017) "terms including "environmentally assisted cracking," "stress corrosion," "time-dependent crack growth," "progressive failure," "microcracking" or "static fatigue" are commonly synonymously employed to describe combined subcritical cracking processes".

Nevertheless, the majority of studies that highlight sub-critical crack propagation focus on subsurface cracking and can explain exfoliation phenomena (Collins et al., 2018; Collins and Stock, 2016; Holzhausen, 1989).

The data collected at la Roque Gageac the shows the possibility of skin phenomena, on the surface, leading to the propagation of cracks due to thermal fatigue, but the mechanism of failure of the large blocks certainly involves some sizable fractures as those due to paleo-karst.

The geometry as well as the thermal and mechanical behaviour of such fractures involves too many uncertainties for their comportment under thermal stresses to be able to be calculated, but they generally have a lower tensile strength than the rock matrix, the predisposition of which we have shown to failure.

\section{Conclusion}

The roof of a limestone perched cave subjected to partial collapse and presenting a residual hazard was monitored during more than five years (after the collapse) until reinforcement works. A body of evidence, detailed in this paper, led us to suspect that temperature variations play a role in crack propagation and possible failures. The first one is that no evidence of other triggering factors for rock fall such as raining, freeze/ thaw cycles or seismic events was identified. Secondly, extensometers in boreholes above the cave, show temperature and displacement decreasing with depth, but they also make it possible to detect an increase in displacements over time. This increase was also detected on the fissurometers placed in the cave and was larger than deep in the rock mass. Finally, analytical consideration computation reinforced this opinion.

As the shape of the cave is simplified, numerical results cannot be precisely compared to the recordings, they can only give orders of magnitude. Nevertheless, it shows that the stress variation in planes parallel to the topographic surface can be close to the tensile strength of the rock matrix and can thus explain a rupture in tensile mode. Moreover, fracture mechanics also show that the registered thermal 
variations can lead to subcritical crack propagation and probably even in the rock mass at a depth of $6 \mathrm{~m}$.

The whole phenomenon of failure mechanism that occurs in La Roque-Gageac limestone cliff is not completely understood because it certainly involves large fractures with undetermined mechanical behaviour. However, a network of observations, measurements and computation led to incriminate natural thermal cycles as one of the potential triggering mechanisms for the rock mass instability in this site.

\section{Declaration of Competing Interest}

The authors declare that they have no known competing financial interests or personal relationships that could have appeared to influence the work reported in this paper.

The authors declare the following financial interests/personal relationships which may be considered as potential competing interests:

\section{References}

Atkinson, B.K., 1982. Subcritical crack propagation in rocks: theory, experimental results and applications. J. Struct. Geol. 4, 41-56. https://doi.org/10.1016/0191-8141(82) 90005-0.

Bakun-Mazor, D., Hatzor, Y.H., Glaser, S.D., Carlos Santamarina, J., 2013. Thermally vs. seismically induced block displacements in Masada rock slopes. Int. J. Rock Mech. Min. Sci. 61, 196-211. https://doi.org/10.1016/j.ijrmms.2013.03.005.

Cloutier, C., Locat, J., Charbonneau, F., Couture, R., 2015. Understanding the kinematic behavior of the active Gascons rockslide from in-situ and satellite monitoring data. Eng. Geol. 195, 1-15. https://doi.org/10.1016/j.enggeo.2015.05.017.

Collins, B.D., Stock, G.M., 2016. Rockfall triggering by cyclic thermal stressing of exfoliation fractures. Nat. Geosci. 9, 395-400. https://doi.org/10.1038/ngeo2686.

Collins, B.D., Stock, G.M., Eppes, M., Lewis, S.W., Corbett, S.C., Smith, J.B., 2018. Thermal influences on spontaneous rock dome exfoliation. Nat. Commun. 9, 1-12. https://doi.org/10.1038/s41467-017-02728-1.

Deprez, M., De Kock, T., De Schutter, G., Cnudde, V., 2020. A review on freeze-thaw action and weathering of rocks. Earth-Science Rev. 203, 103143. https://doi.org/ 10.1016/j.earscirev.2020.103143.

Eppes, M.C., Griffing, D., 2010. Granular disintegration of marble in nature: a thermalmechanical origin for a grus and corestone landscape. Geomorphology 117, 170-180. https://doi.org/10.1016/j.geomorph.2009.11.028.

Eppes, M.C., Keanini, R., 2017. Mechanical weathering and rock erosion by climatedependent subcritical cracking. Rev. Geophys. 55, 470-508. https://doi.org/ 10.1002/2017RG000557.

Eppes, M.C., McFadden, L.D., Wegmann, K.W., Scuderi, L.A., 2010. Cracks in desert pavement rocks: further insights into mechanical weathering by directional insolation. Geomorphology 123, 97-108. https://doi.org/10.1016/j. geomorph.2010.07.003.

Fell, R., Corominas, J., Bonnard, C., Cascini, L., Leroi, E., Savage, W.Z., 2008. Guidelines for landslide susceptibility, hazard and risk zoning for land use planning. Eng. Geol. 102, 85-98. https://doi.org/10.1016/j.enggeo.2008.03.022.

Fortin, J., Gasc-barbier, M., Merrien-soukatchoff, V., 2018. Comportement des roches en température. In: Gasc-Barbier, M., Merrien-Soukatchoff, V., Berest, P. (Eds.), Thermomécanique Des Roches. Presses des Mines, Paris.

Frayssines, M., Hantz, D., 2006. Failure mechanisms and triggering factors in calcareous cliffs of the Subalpine Ranges (French Alps). Eng. Geol. 86, 256-270. https://doi. org/10.1016/j.enggeo.2006.05.009.

Galeandro, A., Doglioni, A., Simeone, V., Šimůnek, J., 2014. Analysis of infiltration processes into fractured and swelling soils as triggering factors of landslides. Environ. Earth Sci. 71, 2911-2923. https://doi.org/10.1007/s12665-013-2666-7.

Gasc-Barbier, M., Merrien-Soukatchoff, V., 2019. Effect of Natural Thermal Cycles on Rock Slopes Stability- Study of 2 French Sites, in: Rock Mechanics for Natural Resources and Infrastructure Development- Proceedings of the 14th International Congress on Rock Mechanics and Rock Engineering, ISRM 2019.

Gasc-Barbier, M., Virely, D., Guittard, J., 2015. Thermal Fatigue in Rocks- la RoqueGageac' Case Study, in: 13th ISRM International Congress of Rock Mechanics. Montreal, Canada.
Gasc-Barbier, M., Merrien-Soukatchoff, V., Villarraga-diaz, C., 2020. Effet de cycles thermiques sur un massif rocheux : observations et mesures au laboratoire et in situ. Rev. Française Géotechnique. https://doi.org/10.1051/geotech/2020013.

Gunzburger, Y., Merrien-Soukatchoff, V., 2011. Near-surface temperatures and heat balance of bare outcrops exposed to solar radiation. Earth Surf. Process. Landf. https://doi.org/10.1002/esp.2167.

Gunzburger, Y., Merrien-Soukatchoff, V., Guglielmi, Y., 2005. Influence of daily surface temperature fluctuations on rock slope stability: Case study of the Rochers de Valabres slope (France). Int. J. Rock Mech. Min. Sci. 42, 331-349. https://doi.org/ 10.1016/j.ijrmms.2004.11.003.

Griffith, A.A., 1924. Theory of rupture. In: Proceedings of the 1st international congress applied mechanics, Delft, the Netherlands, pp. 55-63.

Hall, K., 1999. The role of thermal stress fatigue in the breakdown of rock in cold regions. Geomorphology 31, 47-63. https://doi.org/10.1016/S0169-555X(99)00072-0.

Hall, K., 2004. Evidence for freeze-thaw events and their implications for rock weathering in northern Canada. Earth Surf. Process. Landf. 29, 43-57. https://doi. org/10.1002/esp.1012.

Hall, K., Thorn, C.E., 2014. Thermal fatigue and thermal shock in bedrock: an attempt to unravel the geomorphic processes and products. Geomorphology 206, 1-13. https:// doi.org/10.1016/j.geomorph.2013.09.022.

Hall, K., Thorn, C., Sumner, P., 2012. On the persistence of "weathering". Geomorphology 149-150, 1-10. https://doi.org/10.1016/j.geomorph.2011.12.024. Henry, J.P., Parsy, F., 1982. Cours d'élasticité. Dunod Bordas, Paris, p. 298.

Holzhausen, G.R., 1989. Origin of sheet structure, 1. Morphology and boundary conditions. Eng. Geol. 27, 225-278. https://doi.org/10.1016/0013-7952(89)900355.

Intrieri, E., Gigli, G., Mugnai, F., Fanti, R., Casagli, N., 2012. Design and implementation of a landslide early warning system. Eng. Geol. 147-148, 124-136. https://doi.org/ 10.1016/j.enggeo.2012.07.017.

Marmoni, G.M., Fiorucci, M., Grechi, G., Martino, S., 2020. Modelling of thermomechanical effects in a rock quarry wall induced by near-surface temperature fluctuations. Int. J. Rock Mech. Min. Sci. 134, 104440. https://doi.org/10.1016/j. ijrmms.2020.104440.

Matsuoka, N., 2001. Direct observation of frost wedging in alpine bedrock. Earth Surf. Process. Landf. 26, 601-614. https://doi.org/10.1002/esp.208.

Matsuoka, N., 2008. Frost weathering and Rockwall erosion in the southeastern Swiss Alps: long-term (1994-2006) observations. Geomorphology 99, 353-368. https:// doi.org/10.1016/j.geomorph.2007.11.013.

Meredith, P.G., Atkinson, B.K., 1985. Fracture toughness and subcritical crack growth during high-temperature tensile deformation of Westerly granite and Black gabbro. Phys. Earth Planet. Inter. 39, 33-51. https://doi.org/10.1016/0031-9201(85)90113$\mathrm{X}$.

Merrien-soukatchoff, V., Gasc-barbier, M., 2021. Effect of Thermal Cycles on Rock Outcrops, in: SCG-XIII INTERNATIONAL SYMPOSIUM ON LANDSLIDES. Cartagena, Colombia.

Nguyen, B.Q.V., Lee, S.R., Kim, Y.T., 2020. Spatial probability assessment of landslide considering increases in pore-water pressure during rainfall and earthquakes: Case studies at Atsuma and Mt. Umyeon. Catena 187, 104317. https://doi.org/10.1016/j. catena.2019.104317.

Putot, C., Chastanet, J., Cacas, M.C., Daniel, J.P., 2001. Fracturation naturelle d'un massif rocheux. Diaclases et couloirs de fracturation. Oil \& Gas Science and Technology - Rev. IFP 56, 431-449.

Ravaji, B., Alí-Lagoa, V., Delbo, M., Wilkerson, J.W., 2019. Unraveling the Mechanics of thermal stress Weathering: Rate-Effects, Size-Effects, and Scaling Laws. J. Geophys. Res. Planets 124, 3304-3328. https://doi.org/10.1029/2019JE006019.

Regmi, A.D., Yoshida, K., Dhital, M.R., Devkota, K., 2013. Effect of rock weathering, clay mineralogy, and geological structures in the formation of large landslide, a case study from Dumre Besei landslide, Lesser Himalaya Nepal. Landslides 10, 1-13. https://doi.org/10.1007/s10346-011-0311-7.

Stoffel, M., Tiranti, D., Huggel, C., 2014. Climate change impacts on mass movements Case studies from the European Alps. Sci. Total Environ. 493, 1255-1266. https:// doi.org/10.1016/j.scitotenv.2014.02.102.

Vargas, E.A., Castro, J.T., Amaral, C., Figueiredo, R.P., 2004. On mechanisms for failures of some rock slopes in Rio de Janeiro, Brazil: thermal fatigue?, in: Landslides: Evaluation and Stabilization/Glissement de Terrain: Evaluation et Stabilisation, Set of 2 Volumes, pp. 1007-1011.

Vargas, E.A., Chavez, E., Gusmao, L., Amaral, C., 2009. Is Thermal Fatigue a Possible Mechanism for Failure of some Rock Slope in Rio de Janeiro, Brazil ?, in: ARMA 43th US Rock Mech Symposium (Asheville).

Villarraga, C.J., Gasc-Barbier, M., Vaunat, J., Darrozes, J., 2018. The effect of therma cycles on limestone mechanical degradation. Int. J. Rock Mech. Min. Sci. 109 https://doi.org/10.1016/j.ijrmms.2018.06.017. 